\title{
Prevalence of preclinical Alzheimer disease
}

\section{Comparison of current classification systems}

\author{
Silke Kern, MD, PhD, Henrik Zetterberg, MD, PhD, Jürgen Kern, MD, PhD, Anna Zettergren, PhD, \\ Margda Waern, MD, PhD, Kina Höglund, PhD, Ulf Andreasson, PhD, Hanna Wetterberg, MSc, \\ Anne Börjesson-Hanson, MD, PhD, Kaj Blennow, MD, PhD, and Ingmar Skoog, MD, PhD
}

Neurology ${ }^{\circledR}$ 2018;90:e1682-e1691. doi:10.1212/WNL.0000000000005476

\section{Abstract}

\section{Objective}

To determine the prevalence of preclinical Alzheimer disease (AD) according to current classification systems by examining CSF from a representative general population sample of 70-year-olds from Gothenburg, Sweden.

\section{Method}

The sample was derived from the population-based H70 Gothenburg Birth Cohort Studies in Gothenburg, Sweden. The participants $(n=322$, age 70 years $)$ underwent comprehensive neuropsychiatric, cognitive, and somatic examinations. CSF levels of $\beta$-amyloid $(A \beta)_{42}, A \beta_{40}$, total tau, and phosphorylated tau were measured. Preclinical $\mathrm{AD}$ was classified according to criteria of the A/T/N system, Dubois 2016, National Institute on Aging-Alzheimer's Association (NIA-AA) criteria, and International Working Group-2 (IWG-2) criteria. Individuals with Clinical Dementia Rating score $>0$ were excluded, leaving 259 cognitively unimpaired individuals.

\section{Results}

The prevalence of amyloid pathology was $22.8 \%$, of total tau pathology was $33.2 \%$, and of phosphorylated tau pathology was $6.9 \%$. With the $\mathrm{A} / \mathrm{T} / \mathrm{N}$ system, the prevalence of $\mathrm{A}+/ \mathrm{T}-/$ $\mathrm{N}-$ was $13.1 \%, \mathrm{~A}+/ \mathrm{T}-/ \mathrm{N}+$ was $7.3 \%, \mathrm{~A}+/ \mathrm{T}+/ \mathrm{N}+$ was $2.3 \%, \mathrm{~A}-/ \mathrm{T}-/ \mathrm{N}+$ was $18.9 \%$, and $\mathrm{A}-/$ $\mathrm{T}+/ \mathrm{N}+$ was $4.6 \%$. When the Dubois criteria were applied, the prevalence of asymptomatic at risk for $\mathrm{AD}$ was $36.7 \%$ and of preclinical $\mathrm{AD}$ was $9.7 \%$. With the NIA-AA criteria, the prevalence of stage 1 was $13.1 \%$ and stage 2 was $9.7 \%$. With the IWG-2 criteria, the prevalence of asymptomatic at risk for $\mathrm{AD}$ was $9.7 \%$. The $A P O E \varepsilon 4$ allele was associated with several of the categories. Men more often had total tau pathology, $\mathrm{A}+/ \mathrm{T}-/ \mathrm{N}+$, preclinical $\mathrm{AD}$ according to Dubois 2016, asymptomatic at risk for AD according to the IWG-2 criteria, and NIA-AA stage 2.

\section{Conclusion}

The prevalence of pathologic $\mathrm{AD}$ markers was very common (46\%) in a representative population sample of 70-year-olds. The clinical implications of these findings need to be scrutinized further in longitudinal studies.

\author{
Correspondence \\ Dr. Kern \\ silke.kern@neuro.gu.se
}




\section{Glossary}

$\mathbf{A} \beta=\beta$-amyloid $\mathbf{A D}=$ Alzheimer disease $\mathbf{A R}-\mathbf{A D}=$ at risk for Alzheimer disease $\mathbf{C D R}=$ Clinical Dementia Rating; $\mathbf{C F A S}=$ Cognitive Function and Ageing; DSM-III-R = Diagnostic and Statistical Manual of Mental Disorders, 3rd edition, revised; DSMV = Diagnostic and Statistical Manual of Mental Disorders, 5th edition; IWG-2 = International Working Group-2; LP = lumbar puncture; $\mathbf{M C I}=$ mild cognitive impairment; $\mathbf{M M S E}=$ Mini-Mental State Examination; NIA-AA = National Institute on Aging-Alzheimer's Association; p-tau = phosphorylated tau; SNAP = non-Alzheimer disease pathophysiology; SNP = single nucleotide polymorphism; $\mathbf{t}$-tau $=$ total tau.

The hallmarks of Alzheimer disease $(\mathrm{AD})$ include the aggregation of $\beta$-amyloid $(A \beta)$ into plaques, the hyperphosphorylation of tau protein with the formation of tangles, and brain atrophy. ${ }^{1}$ In neuropathologic series, a large proportion of cognitively normal elderly have Alzheimer pathology. ${ }^{2}$ In the Cognitive Function and Ageing (CFAS) population study, one-fifth of elderly without dementia fulfilled neuropathologic criteria for $\mathrm{AD}$, and one-third had moderate to severe plaque pathology. ${ }^{3}$ The corresponding figure in those with dementia was $59 \%{ }^{3}$ PET studies report amyloid pathology in $\approx 30 \%$ of healthy elderly from control or convenience samples. ${ }^{4-7}$ CSF studies show frequencies ranging from $12 \%$ to $36 \% .^{8-11}$

Most data are derived from convenience samples, e.g., normal controls from memory clinics or volunteers. Data from representative samples are needed to clarify the population prevalence of preclinical $\mathrm{AD}$ pathology.

Biomarkers reflecting the accumulation of $A \beta$ deposition are the earliest sign of $\mathrm{AD}$ in healthy elderly. ${ }^{12,13} \mathrm{~A} \beta$ pathology is detected earlier in CSF than in PET. ${ }^{12,14}$ Brain autopsy and biomarker studies indicate that amyloid pathology is initiated $\approx 10$ to 20 years before clinical symptoms. ${ }^{15}$ Presently, there are 4 different classifications in use for preclinical $\mathrm{AD}$. The most recent, the $\mathrm{A} / \mathrm{T} / \mathrm{N}$ system, was introduced in $2016 .{ }^{16}$ The consensus group-defined criteria for preclinical AD (Dubois criteria) $)^{17}$ came in 2016, the International Working Group-2 (IWG-2) criteria $^{7}$ in 2014, and the National Institute on Aging-Alzheimer's Association (NIA-AA) criteria ${ }^{18,19}$ in 2011. The only classification that differentiates between phosphorylated ( $\mathrm{p}$ )-tau and total $(\mathrm{t}$ )-tau is the $\mathrm{A} / \mathrm{T} / \mathrm{N}$ system. The prevalence of preclinical $\mathrm{AD}$ in accordance with these different classification systems needs to be elucidated in representative population samples. The aim of the current study was to determine the prevalence of preclinical $\mathrm{AD}$ in accordance with the 4 current classification systems based on CSF data from a representative population-based sample of 70-year-olds.

\section{Methods}

The baseline sample was derived from the 2014 to 2016 examinations of the H70 Gothenburg Birth Cohort Studies in Gothenburg, Sweden. The sample was obtained from the Swedish Population Registry and included persons living in private households and individuals in residential care. ${ }^{20}$
Every 70-year-old in Gothenburg, Sweden, born during 1944 on prespecified birthdates was invited to the examination in 2014 to 2016, and 1,203 participated (response rate $72.2 \%)$. Of these, $430(35.8 \%)$ consented to a lumbar puncture (LP). Contraindications (anticoagulant therapy, immune-modulated therapy, cancer therapy) were present in 108 , leaving 322 (26.8\%). CSF volume was insufficient for 4 participants.

For the purpose of the present study, we defined our study cohort as cognitively unimpaired as operationalized by a Clinical Dementia Rating (CDR) score of 0. Thus, participants with CDR score $>0(n=63)$ were excluded, leaving 259 participants with a CDR score of 0 .

\section{Standard protocol approvals, registrations, and patient consents}

All participants and/or their close relatives gave written informed consent. The study was approved by the Regional Ethics Review Board in Gothenburg.

\section{Assessments}

Participants were examined at the neuropsychiatric memory clinic at Sahlgrenska University Hospital in Gothenburg or at home. Experienced psychiatric research nurses performed the neuropsychiatric examinations, which comprised ratings of psychiatric symptoms and signs, and tests of mental functioning, including assessments of episodic memory (shortterm, long-term memory), aphasia, apraxia, agnosia, executive functioning, and personality changes. ${ }^{21-23}$ Key informant interviews were performed by psychiatric research nurses as described previously. ${ }^{21}$

Examinations included the Mini-Mental State Examination (MMSE) and the CDR. A geriatric psychiatrist and neurologist (S.K.) assigned the final ratings.

Dementia was diagnosed according to the DSM-III-R criteria $^{21}$ because these criteria have been used in the Gothenburg studies for $>30$ years.

Stroke and TIA information was acquired from self-reports and key informants. The participants underwent comprehensive somatic examinations. ${ }^{22}$ Education, defined in years of education, was assessed by self-report or close informant information. 


\section{APOE genotyping}

The single nucleotide polymorphisms (SNPs) rs7412 and rs429358 in APOE (gene map locus 19q13.2) were genotyped, with a success rate of $100 \%$, with the KASPar PCR SNP genotyping system (LGC Genomics, Hoddesdon, Herts, UK). Genotype data for these 2 SNPs were used to define the $\varepsilon 2, \varepsilon 3$, and $\varepsilon 4$ alleles.

\section{CSF sampling and biomarker analyses}

LPs to collect CSF samples were performed in the L3-4 or L4-5 interspace in the morning. ${ }^{24}$ The first $10 \mathrm{~mL}$ CSF was collected in a polypropylene tube and immediately transported to the laboratory for centrifugation at $1,800 \mathrm{~g}$ at $20^{\circ} \mathrm{C}$ for 10 minutes. The supernatant was gently mixed to avoid possible gradient effects, divided into aliquots in the polypropylene tubes, and stored at $-70^{\circ} \mathrm{C} .{ }^{10,24}$

CSF total tau (t-tau) and tau phosphorylated at threonine 181 (ptau) were determined with a sandwich enzyme-linked immunosorbent assay (INNOTEST htau Ag and PHOSPHO_TAU [181P], Fujirebio [formerly Innogenetics], Ghent, Belgium). ${ }^{25,26}$ CSF $A \beta_{42}$ was measured with a sandwich enzyme-linked immunosorbent assay (INNOTEST $A \beta_{1-42}$ ) specifically constructed to measure $A \beta$ starting at amino acid 1 and ending at amino acid $42 .{ }^{27}$ For the $A \beta_{42} / A \beta_{40}$ ratio, the V-PLEX $A \beta$ Peptide Panel 1 (6E10) Kit (Meso Scale Discovery, Rockville, $\mathrm{MD}$ ) was used. ${ }^{28}$ All assays are included in the panel of clinical routine analyses at the Mölndal Clinical Neurochemistry laboratory. Analytic runs had to pass quality control criteria for the calibrators, and internal quality control samples had to be approved. The CSF cutoffs in this study were as follows: CSF A $\beta_{42}$ levels $\leq 530 \mathrm{pg} / \mathrm{mL}$, CSF t-tau levels $\geq 350 \mathrm{pg} / \mathrm{mL}$, and $\mathrm{p}$-tau levels $\geq 80 \mathrm{pg} / \mathrm{mL} .^{10}$

\section{A/T/N classification}

According to the $\mathrm{A} / \mathrm{T} / \mathrm{N}$ classification scheme, ${ }^{16}$ each participant was classified into 3 binary categories. A refers to $A \beta$ pathology (CSF $A \beta_{42}$ levels $\leq 530 \mathrm{pg} / \mathrm{mL}$ ), $\mathrm{T}$ to pathologic p-tau (CSF p-tau $\geq 80 \mathrm{pg} / \mathrm{mL}$ ), and $\mathrm{N}$ to neurodegeneration biomarker (CSF t-tau $\geq 350 \mathrm{pg} / \mathrm{mL}$ ). Participants can have 8 possible biomarker combinations.

\section{The Dubois 2016 criteria}

In accordance with the criteria from Dubois et al., ${ }^{17}$ persons with both amyloid and tau pathology were classified as having preclinical $\mathrm{AD}$. Cognitively normal participants (i.e., CDR score 0 ) with either amyloid pathology or tau pathology are considered to be at risk for $\mathrm{AD}$ (AR-AD).

\section{IWG-2 criteria}

According to the IWG-2 criteria, ${ }^{7}$ asymptomatic at risk for $\mathrm{AD}$ is defined as cognitively normal persons (i.e., $\mathrm{CDR}$ score 0 ) with Alzheimer pathology (here defined as CSF A $\beta_{42}$ levels $\leq 530 \mathrm{pg} / \mathrm{mL}$ ) and pathologic CSF t-tau or p-tau (CSF t-tau levels $\geq 350 \mathrm{pg} / \mathrm{mL}$ or p-tau levels $\geq 80 \mathrm{pg} / \mathrm{mL}$ ). We were not able to use the IWG-2 criteria of increased retention of fibrillary amyloid PET.

\section{NIA-AA criteria}

The NIA-AA criteria for preclinical AD include 3 stages. Stage 1 refers to asymptomatic individuals with abnormal amyloid markers; stage 2 refers to asymptomatic individuals with abnormal amyloid and injury markers (markers of neurodegeneration such as high CSF $\mathrm{t}$-tau or p-tau, neuronal dysfunction on fluorodeoxyglucose-PET, cortical thinning, and hippocampal atrophy on MRI); and stage 3 refers to individuals with subtle cognitive changes and abnormal amyloid and injury markers. ${ }^{18}$ An additional category, suspected non$\mathrm{AD}$ pathophysiology (SNAP), defined as abnormal tauopathy without amyloidopathy, was later suggested. ${ }^{19}$ In our study, only stage 1 , stage 2 , and SNAP were included; all were based on CSF injury markers only.

\section{Overlap between current classifications systems}

The following categories coincide here:

1. $\mathrm{A}+/ \mathrm{T}-/ \mathrm{N}-, \mathrm{A}-/ \mathrm{T}-/ \mathrm{N}+$ or $\mathrm{A}-/ \mathrm{T}+/ \mathrm{N}-$, or $\mathrm{A}-/ \mathrm{T}+/ \mathrm{N}+$; AR-AD according to Dubois 2016; and the combination of SNAP (isolated tauopathy) and stage 1 (isolated amyloidopathy) in the NIA-AA criteria.

2. $\mathrm{A}+/ \mathrm{T}+/ \mathrm{N}-, \mathrm{A}+/ \mathrm{T}-/ \mathrm{N}+$, or $\mathrm{A}+/ \mathrm{T}+/ \mathrm{N}+$ according to $\mathrm{A} / \mathrm{T} / \mathrm{N}$; preclinical $\mathrm{AD}$ in the Dubois criteria; stage 2 of the NIA-AA criteria; and asymptomatic at risk for $\mathrm{AD}$ according to the IWG-2 criteria.

3. $\mathrm{A}+/ \mathrm{T}-/ \mathrm{N}-$ and stage 1 according to the NIA-AA criteria.

4. Total pathology of Dubois 2016 criteria and the NIA-AA criteria.

\section{Statistical methods}

Differences in proportions and means were tested with the Fisher exact test and $t$ test.

To address the concern that the prevalence figure could be biased because only $36 \%$ consented to an LP, we used propensity score weighting. First, we conducted a binary regression model in those with CDR score of 0 in the total sample to identify variables that predicted participation in CSF. We considered male sex, education, depression according to DSM-V, self-reported stroke, age, systolic blood pressure, living alone, and income. In a final model, we used male sex, education, depression according to DSM-V, and self-reported stroke. From this, a probability of accepting the CSF was calculated for each person, and the inverse of this probability defined the weights to be used in a weighted calculation of the sample prevalence. The weighted prevalences were very similar to the unweighted (see Results). Because these differences were regarded as trivial, we chose to use unweighted prevalences for the sake of clarity.

A 2-tailed level of significance was used $(p<0.05)$. Statistical analyses were completed with SPSS for Windows (version 17; SPSS, Chicago, IL), SAS (version 9.4; SAS Institute Inc, Cary, NC), or STATA (version 14; StataCorp, College Station, TX). 


\section{Data availability statement}

The authors state that anonymized data on which the article is based will be shared by request from any qualified investigator.

\section{Results}

Table 1 gives the baseline characteristics of participants and nonparticipants in the CSF examination. The dementia prevalence for the entire sample was $2.3 \%(n=28)$.

Those who were excluded from the LP because of contraindications $(\mathrm{n}=108)$ were similar regarding age, sex, MMSE score, living alone, years of education, economic status, and prevalence of dementia and depression, but they had more often had strokes and had lower mean systolic and diastolic blood pressures than participants with CSF data (table 1). Among those with CSF, 259 (80.4\%) had a CDR score of 0, $60(18.6 \%)$ had a CDR score of 0.5 , and $3(0.009 \%)$ had a CDR score of 1 . Participants with CSF were similar to the rest of the sample regarding age, MMSE score, mean systolic and diastolic blood pressures, education, economic status, living alone, and prevalence of stroke, dementia, and depression, but they were more often male (table 1). The coefficient of variation for the different quality control samples used for each biomarker assay was in the interval of $3.6 \%$ to 9.9\% (table e-1, links.lww.com/WNL/A424). The CSF biomarker levels, ranges, and variations are given in table e-2. The distributions for $A \beta_{42}$, t-tau, and $p$-tau were slightly skewed; therefore, the mean and median were provided. $A \beta_{40}$ was normally distributed. The distributions for $\mathrm{A} \beta_{42}, \mathrm{t}$-tau, and p-tau were similar to those seen in Alzheimer's Disease Neuroimaging Initiative ${ }^{29}$ (table e-2).

Despite the small number, those with dementia $(\mathrm{n}=5)$ had a lower mean level of $\mathrm{A} \beta_{42}$ ( $428.2 \mathrm{vs} 718.9 \mathrm{ng} / \mathrm{L}, p=0.004$ ), lower $\mathrm{A} \beta_{40}$ level $(4,781.8$ vs $6,220.3 \mathrm{pg} / \mathrm{mL}, p=0.02)$, lower $\mathrm{A} \beta_{42} / \mathrm{A} \beta_{40}$ ratio (0.55 vs 0.87 ), higher t-tau level (531.2 vs $331.1 \mathrm{ng} / \mathrm{L}, p=0.001$ ), and higher $\mathrm{p}$-tau level (67.6 vs $49.4 \mathrm{ng} / \mathrm{L}, p=0.021$ ) than those without dementia (table e-2, links.lww.com/WNL/A424).

Among those without dementia, there was no difference between those with a CDR score of $0.5(\mathrm{n}=57)$ and those with a CDR score of $0(\mathrm{n}=259)$ in $\mathrm{A} \beta_{42}(697.4$ vs $724.5 \mathrm{ng} / \mathrm{L}, p=$ $0.41), A \beta_{40}(6,052.7$ vs $6,250.9 \mathrm{pg} / \mathrm{mL}, p=0.31), \mathrm{A} \beta_{42} / \mathrm{A} \beta_{40}$ ratio ( 0.86 vs $0.88, p=0.53) \mathrm{t}$-tau (328.3 vs $332.0 \mathrm{ng} / \mathrm{L}, p=$ 0.83 ), and p-tau (49.1 vs $49.5 \mathrm{ng} / \mathrm{L}, p=0.86$ ) levels.

The analyses that follow include only those with a CDR score of 0 because a CDR score of 0.5 is an exclusion criterion in all classifications.

\section{Prevalence of amyloid and tau pathology}

Among those with a CDR score of 0 , the prevalence of amyloid pathology was $22.8 \%$, of $t$-tau pathology was $33.2 \%$, and of p-tau pathology was $6.9 \%$ (table 2). The weighted prevalence of amyloid pathology was $22.5 \%$, of $\mathrm{t}$-tau pathology was $33.7 \%$, and of p-tau pathology was $7.1 \%$. Because these differences must be regarded as trivial, we chose to use unweighted prevalences in the rest of the results for the sake of clarity.

Table 1 Characteristics of a representative population-based sample of 70-year-olds by LP participation status

\begin{tabular}{|c|c|c|c|c|c|c|}
\hline & $\operatorname{CSF}(n=322)$ & $\begin{array}{l}\text { Excluded from CSF } \\
(n=108)\end{array}$ & $\begin{array}{l}\text { Declined CSF } \\
(n=772)\end{array}$ & $p$ Value $^{a}$ & $p$ Value $^{b}$ & $p$ Value $^{c}$ \\
\hline Age, mean (SD), y & $70.6(0.3)$ & $70.6(0.3)$ & $70.5(0.3)$ & 0.58 & 0.56 & 0.12 \\
\hline MMSE score, mean (SD) & $28.9(1.4)$ & $28.7(2.1)$ & $28.9(2.3)$ & 0.73 & 0.68 & 0.75 \\
\hline Systolic blood pressure, mean (SD) & $139.6(17.2)$ & $132.9(15.6)$ & $140.6(20.1)$ & 0.0004 & 0.42 & 0.02 \\
\hline Diastolic blood pressure, mean (SD) & $79.5(9.3)$ & $76.6(8.6)$ & $79.6(10.2)$ & 0.0037 & 0.98 & 0.2 \\
\hline Education, mean (SD), y & $12.4(3.5)$ & $13.1(3.8)$ & $12.8(3.8)$ & 0.08 & 0.096 & 0.3 \\
\hline Total household income, mean (SD), SEK ${ }^{\mathrm{d}}$ & $38.130(21.713)$ & $40.316(23.249)$ & $38.771(24.830)$ & 0.42 & 0.73 & 0.97 \\
\hline Women, n (\%) & $155(48)$ & $47(43.5)$ & $440(57.0)$ & 0.44 & 0.012 & 0.0014 \\
\hline Living alone, n (\%) & $111(34.9)$ & $40(38.5)$ & $281(36.9)$ & 0.59 & 0.60 & 0.73 \\
\hline Stroke, n (\%) & $14(4.4)$ & $20(18.5)$ & $43(5.7)$ & 0.00001 & 0.45 & 0.18 \\
\hline Dementia, n (\%) & $5(1.6)$ & $5(4.6)$ & $18(2.3)$ & 0.13 & 0.56 & 0.85 \\
\hline Any depression, n (\%) & $30(9.3)$ & $5(4.7)$ & $72(9.3)$ & 0.19 & 0.94 & 0.54 \\
\hline
\end{tabular}

Abbreviations: $L P=$ lumbar puncture; MMSE = Mini-Mental State Examination; SEK = Swedish krona.

a Test of the difference in means and proportions between CSF participants $(n=322)$ and those excluded because of contraindications ( $n=108)$.

b Test of difference in means and proportions between CSF participants $(n=322)$ and participants who declined an LP ( $n=722)$.

${ }^{c}$ Test of difference in means and proportions between all participants who consented to undergo an LP $(n=430)$ and participants who declined the LP ( $\mathrm{n}=$ 772).

d Total gross household income in SEK. 
Table 2 Prevalence of amyloid and tau pathology according to the A/T/N classification scheme, Dubois 2016 criteria, IWG2 criteria, and NIA-AA criteria and in a representative population-based sample of 70-year-olds with a CDR score of 0

\begin{tabular}{|c|c|c|c|c|}
\hline & Men $(n=130)$ & Women $(n=129)$ & & All $(n=259)$ \\
\hline & n (\%) & n (\%) & $p$ Value $^{a}$ & n (\%) \\
\hline Amyloid pathology & $34(26.2)$ & $25(19.4)$ & 0.236 & $59(22.8)$ \\
\hline t-Tau pathology & $52(40.0)$ & $34(26.4)$ & 0.025 & $86(33.2)$ \\
\hline p-Tau pathology & $9(6.9)$ & $9(7.0)$ & 1.00 & $18(6.9)$ \\
\hline \multicolumn{5}{|l|}{ A/T/N classification 2016} \\
\hline $\mathrm{A}+/ \mathrm{T}-/ \mathrm{N}-$ & $15(11.5)$ & $19(14.7)$ & 1.0 & $34(13.1)$ \\
\hline $\mathrm{A}+/ \mathrm{T}+/ \mathrm{N}-$ & $0(0)$ & $0(0)$ & & $0(0)$ \\
\hline $\mathrm{A}+/ \mathrm{T}-/ \mathrm{N}+$ & $14(5.4)$ & $5(1.9)$ & 0.03 & $19(7.3)$ \\
\hline $\mathrm{A}+/ \mathrm{T}+/ \mathrm{N}+$ & $5(1.9)$ & $1(0.4)$ & 0.09 & $6(2.3)$ \\
\hline $\mathrm{A}-/ \mathrm{T}+/ \mathrm{N}-$ & $0(0)$ & $0(0)$ & & $0(0)$ \\
\hline $\mathrm{A}-/ \mathrm{T}-/ \mathrm{N}+$ & $29(11.2)$ & $20(7.7)$ & 0.10 & 49 (18.9) \\
\hline $\mathrm{A}-/ \mathrm{T}+/ \mathrm{N}+$ & $4(1.5)$ & $8(3.1)$ & 0.55 & $12(4.6)$ \\
\hline \multicolumn{5}{|l|}{ Dubois criteria 2016} \\
\hline AR-AD & $48(36.9)$ & $47(37.4)$ & 0.5 & $95(36.7)$ \\
\hline Preclinical AD & $19(14.6)$ & $6(4.7)$ & 0.008 & $25(9.7)$ \\
\hline \multicolumn{5}{|l|}{ IWG-2 criteria $2014^{\mathrm{b}}$} \\
\hline Asymptomatic at risk for Alzheimer disease & $19(14.6)$ & $6(4.7)$ & 0.008 & $25(9.7)$ \\
\hline \multicolumn{5}{|l|}{ NIA-AA criteria 2011} \\
\hline Stage 1 & $15(11.5)$ & $19(14.7)$ & 1.0 & $34(13.1)$ \\
\hline Stage $2^{c}$ & $19(14.6)$ & $6(4.7)$ & 0.008 & $25(9.7)$ \\
\hline SNAPd & $33(25.4)$ & $28(21.7)$ & 0.28 & $61(23.6)$ \\
\hline \multicolumn{5}{|c|}{$\begin{array}{l}\text { Abbreviations: AD = Alzheimer disease; AR-AD = at risk of Alzheimer disease; CDR = Clinical Dementia Rating; IWG-2 = International Working Group-2; NIA-AA= } \\
\text { National Institute on Aging-Alzheimer's Association; } \mathrm{p} \text {-tau = phosphorylated tau; SNAP = suspected non-Alzheimer disease pathophysiology; t-tau = total tau. } \\
\text { a Fisher exact test was used to test differences in proportions, and a 2-tailed level of significance was used. } \\
\text { b According to the IWG-2 criteria, asymptomatic at risk for Alzheimer disease is present when there is absence of specific clinical phenotype (absence of amnestic } \\
\text { syndrome of the hippocampal type and absence of clinical phenotype of atypical AD). The IWG-2 criteria also include increased retention of fibrillary amyloid PET as in } \\
\text { vivo evidence of Alzheimer pathology. Because amyloid PET was not available in this study, solely CSF data were used as in vivo evidence of Alzheimer pathology. } \\
\text { c In the current study, only CSF tauopathy is considered because we lacked data for MRI and fluorodeoxyglucose-PET markers of neurodegeneration. } \\
\text { d SNAP was proposed in } 2012 \text { by Jack et al. }{ }^{19} \text { after the initial NIA-AA criteria were introduced. }\end{array}$} \\
\hline
\end{tabular}

\section{A/T/N system}

The prevalence of $\mathrm{A}+/ \mathrm{T}-/ \mathrm{N}-$ was $13.1 \%$, of $\mathrm{A}+/ \mathrm{T}-/ \mathrm{N}+$ was 7.3\%, of $\mathrm{A}+/ \mathrm{T}+/ \mathrm{N}+$ was $2.3 \%$, of $\mathrm{A}-/ \mathrm{T}-/ \mathrm{N}+$ was $18.9 \%$, and of $\mathrm{A}-/ \mathrm{T}+/ \mathrm{N}+$ was $4.6 \%$. No participants had the biomarker combination $\mathrm{A}+/ \mathrm{T}+/ \mathrm{N}-$ and $\mathrm{A}-/ \mathrm{T}+/ \mathrm{N}-$ (table 2 and a Venn diagram in the figure).

\section{Dubois 2016 criteria}

The prevalence of AR-AD was $36.7 \%$ and the prevalence of preclinical $\mathrm{AD}$ 9.7\%. Thus, in total, $46.4 \%$ had $\mathrm{AR}-\mathrm{AD}$ or preclinical $\mathrm{AD}$ (table 2 ).

\section{IWG-2 criteria}

The prevalence of asymptomatic at risk for $\mathrm{AD}$ according to the IWG-2 criteria was $9.7 \%$ (table 2 ).

\section{NIA-AA criteria}

The prevalence of NIA-AA stage 1 was $13.1 \%$, of stage 2 was $9.7 \%$, and of SNAP was $23.6 \%$ (table 2 ).

The CSF biomarker levels, ranges, and variations in the different classification systems are given in table e-3, links.lww. com/WNL/A424.

\section{APOE \&4}

Among persons with a CDR score of $0, A P O E \varepsilon 4$ allele carrier $(\mathrm{n}=86)$ had lower $\mathrm{A} \beta_{42}(606.4$ vs $785.3 \mathrm{ng} / \mathrm{L}, p \leq 0.0001)$, lower $A \beta_{42} / A \beta_{40}$ ratio $(0.76$ vs $0.94, p<0.00001)$, higher t-tau (375.5 vs $311.0 \mathrm{ng} / \mathrm{L}, p=0.0005$ ), and higher $\mathrm{p}$-tau ( $54.6 \mathrm{vs}$ $47.1 \mathrm{ng} / \mathrm{L}, p=0.0016)$ levels compared to APOE $\varepsilon 4$ noncarriers $(n=168)$ (table e-4, links.lww.com/WNL/A424). 
Figure Venn diagram

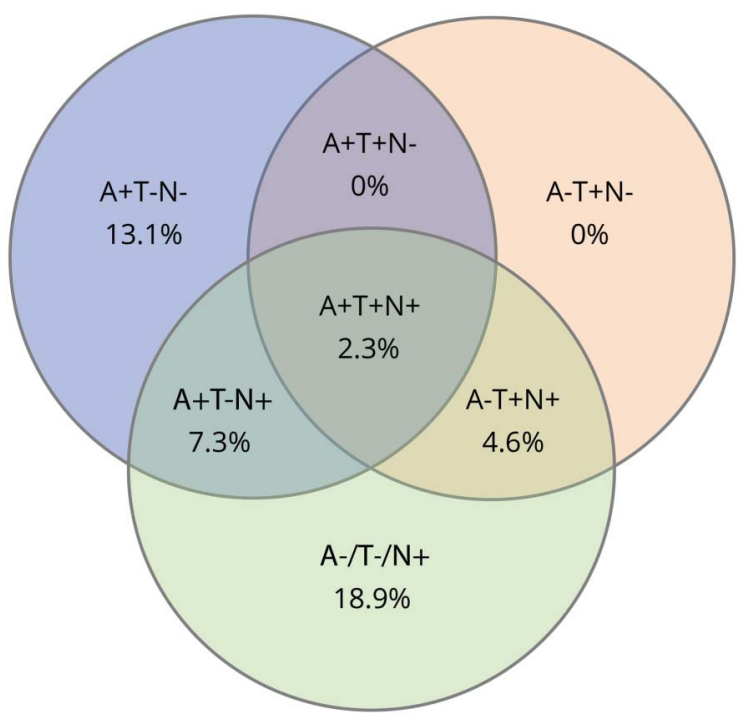

Venn diagram of the ATN distribution of amyloid and tau pathology according to the A/T/N classification scheme in a representative populationbased sample of 70-year-olds with a Clinical Dementia Rating score of 0 . A+ refers to $A \beta$ pathology (CSF $A \beta_{42}$ levels $\leq 530 \mathrm{pg} / \mathrm{mL}$ ), T+ to pathologic $p$-tau (CSF p-tau $\geq 80 \mathrm{pg} / \mathrm{mL}$ ), and $\mathrm{N}+$ to neurodegeneration biomarker (CSF total tau $\geq 350 \mathrm{pg} / \mathrm{mL}$ ) in 259 cognitively normal elderly all 70 years of age. $A \beta=$ $\beta$-amyloid; $p$-tau $=$ phosphorylated tau.

There was no difference in $A \beta_{40}$ levels (6,319.1 vs $6,237.9 \mathrm{pg} / \mathrm{mL}, p=0.89)$. All participants with pathologic values for all 3 biomarkers $(\mathrm{n}=8)$ were APOE $\varepsilon 4$ carriers. Among participants with dementia $(n=5), 4$ had the APOE $\varepsilon 4$ allele $(p=0.017)$.

The APOE $\& 4$ allele was more common in participants with $\mathrm{A}+/ \mathrm{T}-/ \mathrm{N}-, \mathrm{A}+/ \mathrm{T}-/ \mathrm{N}+$, and $\mathrm{A}+/ \mathrm{T}+/ \mathrm{N}+; \mathrm{AR}-\mathrm{AD}$ and preclinical $\mathrm{AD}$ according to Dubois 2016 criteria; stage 1 and stage 2 according to NIA-AA criteria; and asymptomatic at risk for Alzheimer disease according to the IWG-criteria (tables 3-5).

\section{Other characteristics}

Men more often than women had t-tau pathology $\mathrm{A}+/ \mathrm{T}-/ \mathrm{N}+$, preclinical $\mathrm{AD}$ according to Dubois 2016, asymptomatic at risk for Alzheimer disease according to the IWG-2 criteria, and NIA-AA stage 2 (tables 3-5). Participants with $\mathrm{A}+/ \mathrm{T}+/ \mathrm{N}+$ had a lower mean MMSE score (28.5 vs 29.3, $p=0.04$ ) than other participants. There were no differences between different categories and participants with normal CSF values regarding age, living alone, prevalence of depression, stroke, and years of education (tables 3-5).

\section{Analyses of 70-year-olds with good cognition}

Finally, we examined the subgroup scoring 30 on the MMSE. The prevalence of the different categories of preclinical $\mathrm{AD}$ was similar in this group compared to the rest of the sample with a CDR score of 0 (tables 3-5). None of the participants with $\mathrm{A}+/ \mathrm{T}+/ \mathrm{N}+$ had an MMSE score of 30 .

\section{Discussion}

We applied CSF data from a population study to determine the prevalence of preclinical dementia and related conditions in accordance with 4 commonly used classification systems. $\mathrm{AD}$ pathology was observed in almost one-half of the 70-yearolds with a CDR score of 0 . Almost one-fourth had amyloid pathology and a third had tau pathology, representing neuronal injury. Our findings show that amyloid and tau pathology on CSF is very common in cognitively normal populations, as previously shown in neuropathologic series and in convenience samples using PET. ${ }^{2,30}$

Regarding the $\mathrm{A} / \mathrm{T} / \mathrm{N}$ system, we report findings nearly identical to those in a recent report from the Mayo Clinic on persons 50 to 95 years of age for $\mathrm{A}-/ \mathrm{T}+/ \mathrm{N}+(4 \%$ vs $4.6 \%$ in our study), $\mathrm{A}+/ \mathrm{T}-/ \mathrm{N}-(10 \%$ vs $13.1 \%$ in our study), and $\mathrm{A}+/ \mathrm{T}-/ \mathrm{N}+(8 \%$ vs $7.3 \%$ in our study $) .{ }^{31}$ The lower prevalence of $\mathrm{A}+/ \mathrm{T}+/ \mathrm{N}+$ in the current study probably reflects our population-based design. We did not find any cases of $\mathrm{A}+/ \mathrm{T}+/ \mathrm{N}-$ and $\mathrm{A}-/ \mathrm{T}+/ \mathrm{N}-$, suggesting that pathologic CSF p-tau is highly correlated to pathologic CSF t-tau in a population sample of cognitively intact older people. In addition, it is of interest that we found some cases with A-/ $\mathrm{T}+/ \mathrm{N}+(4.6 \%)$ because $\mathrm{T}+$ is not supposed to occur in the absence of abnormal brain amyloidosis. However, this may reflect primary age-related tauopathy, ${ }^{31,32}$ in which neurofibrillary tangles in brains without amyloid $(\mathrm{A} \beta)$ plaques are indistinguishable from neurofibrillary tangles in those with $\mathrm{AD}$. It is also noteworthy that we found more cases with $\mathrm{t}$-tau pathology than with p-tau pathology. These findings may reflect a combination of primary age-related tauopathy and other non- $\mathrm{AD}$ pathologies such as vascular disease or Lewy bodies.

With the use of the Dubois 2016 criteria, slightly more than a third were classified as asymptomatic $\mathrm{AR}-\mathrm{AD}$, and another $1 / 10$ th had preclinical AD. Regarding the NIA-AA criteria, another study, in cognitively normal volunteers (mean age 66 years), ${ }^{8}$ reported that the combined prevalence for stage 1 and SNAP (same as Dubois AR-AD) was 31\%, a figure slightly lower than in our study (36.7\%). That study also reported that $12.3 \%$ had isolated amyloid pathology (stage 1), a figure almost identical to that in our study (13.1\%). The proportion of participants with CSF amyloid or tau pathology in accordance with IWG-2 criteria (46\%) in our study parallels findings based on Alzheimer's Disease Neuroimaging Initiative data. ${ }^{33}$

We found that $23 \%$ had CSF amyloid pathology. This figure is similar to those reported from neuropathologic series of older people $^{2}$ and from convenience samples using PET scans in which $20 \%$ to $30 \%$ are Pittsburgh compound B PET positive. ${ }^{30,34}$ Using CSF, 1 Swedish study, conducted in cognitively healthy elderly volunteers (mean age 72 years) recruited through advertisement, reported that $27 \%$ had $\mathrm{A} \beta_{1-42}$ levels below the study cutoff, ${ }^{11}$ thus paralleling our 
Table 3 Characteristics of a representative sample of 70-year-olds by A/T/N category

\begin{tabular}{|c|c|c|c|c|c|c|c|c|c|c|c|}
\hline & Normal CSF & $\mathrm{A}+/ \mathrm{T}-/ \mathrm{N}-$ & $p$ Value $^{a}$ & $\mathrm{~A}+/ \mathrm{T}-/ \mathrm{N}+$ & $p$ Value $^{a}$ & $\mathrm{~A}+/ \mathrm{T}+/ \mathrm{N}+$ & $p$ Value $^{a}$ & $\mathrm{~A}-/ \mathrm{T}-/ \mathrm{N}+$ & $p$ Value $^{a}$ & $\mathrm{~A}-/ \mathrm{T}+/ \mathrm{N}+$ & P Value ${ }^{a}$ \\
\hline Women, n (\%) & 76 (54.7) & 19 (55.8) & 1.0 & $5(26.3)$ & 0.03 & $1(1.7)$ & 0.10 & $20(40.8)$ & 0.10 & $8(6.7)$ & 0.55 \\
\hline Living alone, n (\%) & $50(36.5)$ & $10(30.3)$ & 0.55 & $6(31.6)$ & 0.8 & $3(50)$ & 0.67 & $16(32.7)$ & 0.73 & $3(25.0)$ & 0.54 \\
\hline Any depression, n (\%) & $14(10.1)$ & $2(5.9)$ & 0.74 & 0 & 0.22 & $21(8.1)$ & 1.0 & $4(8.2)$ & 1.0 & $1(8.3)$ & 1.0 \\
\hline Stroke, n (\%) & $6(4.4)$ & $2(5.9)$ & 0.66 & $0(0)$ & 1.0 & $1(16.7)$ & 0.26 & $1(2.0)$ & 0.68 & $0(0)$ & 1.0 \\
\hline APOE $\varepsilon 4$ allele, $n(\%)$ & $31(23)$ & $19(55.9)$ & 0.0005 & $9(50.0)$ & 0.02 & $6(100.0)$ & 0.0003 & $15(30.6)$ & 0.34 & $6(50.0)$ & 0.07 \\
\hline CDR SOB $=0, n(\%)$ & $133(95.7)$ & $33(97.1)$ & 1.0 & $17(89.5)$ & 0.25 & $6(100.0)$ & 1.0 & $49(100.0)$ & 0.34 & $12(100.0)$ & 1.0 \\
\hline MMSE score = 30, n (\%) & $70(50.4)$ & $18(52.9)$ & 0.85 & $9(47.4)$ & 1.0 & $0(0)$ & 0.03 & $26(54.2)$ & 0.74 & $6(50.0)$ & 1.0 \\
\hline Age, y & $70.9(0.3)$ & $70.9(0.3)$ & 0.75 & $71.0(0.4)$ & 0.20 & $70.7(0.3)$ & 0.11 & $70.9(0.4)$ & 0.58 & $70.9(0.3)$ & 0.93 \\
\hline Education, y & $13.0(3.8)$ & $13.6(3.4)$ & 0.36 & $12.5(3.0)$ & 0.6 & $11.5(4.5)$ & 0.37 & $13.3(3.7)$ & 0.57 & $11.7(2.3)$ & 0.25 \\
\hline MMSE score & $29.3(0.9)$ & $29.4(0.8)$ & 0.70 & $29.3(0.8)$ & 0.91 & $28.5(1.2)$ & 0.04 & $29.3(1.1)$ & 0.82 & $29.2(0.9)$ & 0.66 \\
\hline
\end{tabular}

Abbreviations: $C D R=$ Clinical Dementia Rating; MMSE = Mini-Mental State Examination; SOB = sum of boxes.

a Test of differences in means ( $t$ test) and proportions (Fisher exact test) between the different groups compared to participants with normal CSF values. 
Table 4 Characteristics of asymptomatic AR-AD and preclinical AD according to the Dubois 2016 criteria of a representative sample of 70-year-olds

\begin{tabular}{|c|c|c|c|c|c|}
\hline & Normal CSF & AR-AD & $p$ Value $^{a}$ & Preclinical AD & $p$ Value $^{b}$ \\
\hline Women, n (\%) & $76(54.7)$ & $47(49.5)$ & 0.5 & $6(24.0)$ & 0.008 \\
\hline Living alone, n (\%) & $50(36.5)$ & $29(30.9)$ & 0.47 & $9(36.0)$ & 1.0 \\
\hline Any depression, n (\%) & $14(10.1)$ & $7(7.4)$ & 0.64 & $0(0)$ & 0.22 \\
\hline Stroke, n (\%) & $6(4.4)$ & $3(3.2)$ & 0.73 & $1(4.0)$ & 1.0 \\
\hline APOE \&4 allele, $\mathrm{n}(\%)$ & $31(23.0)$ & $40(42.1)$ & 0.0015 & $15(62.5)$ & 0.0001 \\
\hline CDR SOB = 0, n (\%) & $133(95.7)$ & $94(98.9)$ & 0.25 & $23(92.0)$ & 0.35 \\
\hline MMSE score = 30, n (\%) & $70(50.4)$ & $50(52.6)$ & 0.69 & $9(36.0)$ & 0.19 \\
\hline Age at examination, mean (SD), y & $70.9(0.34)$ & $70.9(0.38)$ & 0.82 & $70.9(0.43)$ & 0.60 \\
\hline Education, mean (SD), y & $13.0(3.8)$ & $13.2(3.5)$ & 0.62 & $12.2(3.3)$ & 0.34 \\
\hline MMSE score, mean (SD) & $29.3(0.9)$ & $29.3(0.98)$ & 0.92 & $29.1(0.95)$ & 0.3 \\
\hline
\end{tabular}

Abbreviations: $A D=$ Alzheimer disease; $A R-A D=$ at risk of Alzheimer disease; $C D R=$ Clinical Dementia Rating; $M M S E=$ Mini-Mental State Examination; SOB = sum of boxes.

a Test of differences in means ( $t$ test) and proportions (Fisher exact test) between participants with asymptomatic AR-AD (according to the Dubois criteria 2016) and participants with normal CSF values.

${ }^{b}$ Test of differences in means ( $t$ test) and proportions (Fisher exact test) between participants with preclinical AD (according to the new Dubois criteria) and participants with normal CSF values.

findings. Our figure is also similar (27\%) to a US study of volunteers. ${ }^{9}$ The concordance between our findings and those from convenience samples is striking, despite the fact that our sample is representative and selected only on the basis of birthdates, while convenience samples are selected on the basis of, for example, advertisements, relatives of memory clinic patients, volunteers, or veterans.
Our study is based solely on data for persons 70 years of age. A higher figure would be anticipated in older age groups because there is strong evidence that amyloid pathology increases with age. ${ }^{30,35}$ A meta-analysis reported a gradual increase with age in the frequency of amyloid pathology based on PET and CSF data from $10 \%$ at 50 years of age to $44 \%$ at 90 years of age in cognitively normal participants. ${ }^{35}$

Table 5 Characteristics of a representative sample of 70-year-olds by preclinical dementia pathology category

\begin{tabular}{|c|c|c|c|c|c|c|c|}
\hline & Normal CSF & Stage 1 & $p$ Value $^{a}$ & Stage 2 and IWG-2 & $p$ Value $^{b}$ & SNAP & $p$ Value $^{c}$ \\
\hline Women, n (\%) & $76(54.7)$ & 19 (55.9) & 1.0 & $6(24.0)$ & 0.008 & $28(45.9)$ & 0.28 \\
\hline Living alone, n (\%) & $50(36.5)$ & $10(30.3)$ & 0.55 & $9(36.0)$ & 1.0 & $19(31.1)$ & 0.52 \\
\hline Any depression, $\mathrm{n}(\%)$ & $14(10.1)$ & $2(5.9)$ & 0.74 & $0(0)$ & 0.13 & $5(8.2)$ & 0.79 \\
\hline Stroke, n (\%) & $6(4.4)$ & $2(5.9)$ & 0.66 & $1(4.0)$ & 1.0 & $1(1.6)$ & 0.68 \\
\hline APOE $\varepsilon 4$ allele, $n(\%)$ & $31(23.0)$ & 19 (55.9) & 0.0006 & $15(62.5)$ & 0.0003 & $21(34.4)$ & 0.12 \\
\hline CDR SOB 0, n (\%) & $133(95.7)$ & $33(97.1)$ & 1.0 & $23(92.0)$ & 0.35 & $61(100)$ & 0.18 \\
\hline MMSE score = 30, n (\%) & $70(50.4)$ & $18(52.9)$ & 0.85 & $9(36)$ & 0.2 & $32(53.3)$ & 0.76 \\
\hline Age at examination, mean (SD), y & $70.9(0.34)$ & $70.8(0.32)$ & 0.75 & $70.9(0.43)$ & 0.6 & $70.9(0.41)$ & 0.53 \\
\hline Education, mean (SD), y & $13.0(3.8)$ & $13.6(3.4)$ & 0.36 & $12.2(3.3)$ & 0.38 & 12.9 (3.5) & 0.9 \\
\hline MMSE score, mean (SD) & $29.3(0.9)$ & $29.4(0.7)$ & 0.69 & $29.1(0.95)$ & 0.3 & $29.3(1.0)$ & 0.72 \\
\hline
\end{tabular}

Abbreviations: $C D R=$ Clinical Dementia Rating; IWG-2 = International Working Group-2; MMSE = Mini-Mental State Examination; SNAP = suspected nonAlzheimer disease pathophysiology; SOB = sum of boxes.

${ }^{a}$ Test of differences in means and proportions between the participants with stage 1 (according to the National Institute on Aging-Alzheimer's Association [NIA-AA] criteria 2011) and participants with normal CSF values.

${ }^{b}$ Test of differences in means and proportions between participants with stage 2 (according to the NIA-AA criteria 2011) and participants with normal CSF values. Asymptomatic at risk for Alzheimer disease according to the IWG-2 criteria is identical to stage 2 according to NIA-AA 2011.

${ }^{c}$ Test of differences in means and proportions between the participants with SNAP (according to the NIA-AA criteria 2011) and participants with normal CSF values. 
We observed associations between $A P O E \& 4$ carriership and all 3 biomarkers, as well as with the criteria of $\mathrm{A}+/ \mathrm{T}-/ \mathrm{N}-, \mathrm{A}+$ $/ \mathrm{T}-/ \mathrm{N}+$, and $\mathrm{A}+/ \mathrm{T}+/ \mathrm{N}+$. A recent study using the $\mathrm{A} / \mathrm{T} / \mathrm{N}$ system showed that participants with $\mathrm{A}+$ were twice as often APOE $\& 4$ carriers than participants without $\mathrm{A}+.^{31}$ In line with some previous studies, carriage of $A P O E \& 4$ was related to AR$\mathrm{AD}$ and preclinical $\mathrm{AD}$ according to Dubois, as well as stage 1 and stage 2 according to NIA-AA and asymptomatic at risk for Alzheimer disease according to IWG-2 criteria. One study using the NIA-AA criteria found that the proportion of preclinical $\mathrm{AD}$ (NIA-AA stage 1-3) was higher in APOE \&4 carriers compared to noncarriers. ${ }^{9}$ Another study found that $A P O E \& 4$ carriers more often had preclinical $A D{ }^{8}$ In a study on cognitively normal persons in the age span of 30 to 90 years, $A P O E \& 4$ carriers more often had amyloid positivity on PET after 70 years of age. ${ }^{36}$

We also found some sex differences. Pathological t-tau, A+/ $\mathrm{T}-/ \mathrm{N}+$, preclinical $\mathrm{AD}$ according to Dubois, asymptomatic at risk for Alzheimer disease according to IWG-2, and NIA-AA stage 2 were more common in men. Another study reported no sex differences with the $\mathrm{A} / \mathrm{T} / \mathrm{N}$ system, although it noted a trend for a higher proportion of men in the $\mathrm{A}-/ \mathrm{T}-/ \mathrm{N}+$ group and the greatest proportion of women in the $\mathrm{A}+/ \mathrm{T}-/ \mathrm{N}-$ group. ${ }^{31}$ Men may have accumulated more nonspecific brain pathology as reflected in t-tau levels as a result of lifestyle choices such as alcohol abuse, head trauma, or vascular risk factors. The higher prevalence of preclinical $\mathrm{AD}$ in men among 70 -year-olds is also noteworthy because later in life, after 85 to 90 years of age, clinical AD is more common in women. It could be that men with preclinical $\mathrm{AD}$ do not survive to the clinical stages, thus leading to higher prevalence of clinical $\mathrm{AD}$ in surviving women beyond 85 years of age. These questions can be answered only by longitudinal follow-up. Sex differences in preclinical $\mathrm{AD}$ need to be studied further.

MMSE score did not differ between those with and those without preclinical $\mathrm{AD}$ as identified by the different $\mathrm{AD}$ pathology classification systems, with the exception of the A+/ $\mathrm{T}+/ \mathrm{N}+$ group. Others report lower MMSE scores in preclinical AD. ${ }^{9}$ This disparity may be related in part to the population-based nature of our study. The cases of AR-AD and preclinical $\mathrm{AD}$, stage 1 , stage 2 , and SNAP identified in our study likely represent an early stage in the disease process. This is further supported by the high mean MMSE scores $(\approx 29)$ and the observation that the prevalence figures were similar in those with an MMSE score of 30. The fact that we found lower MMSE levels only in participants with pathologic levels of all 3 biomarkers suggests that these are probably closer to conversion to mild cognitive impairment (MCI). We could not show this for amyloid positivity and signs of neurodegeneration alone, indicating that tauopathy plays a significant role in the conversion to MCI. Further support for this comes from a study that found that the progression rate to a CDR score $\geq 0.5$ was $5 \%$ for stage 1 and $46 \%$ for stage $2+$, again showing that the combined pathology of amyloidopathy and neuronal injury is driving the conversion. ${ }^{8}$
The conversion rate to MCI and dementia in asymptomatic individuals with amyloid and tau pathology is still unclear. Given the overall low dementia incidence in septuagenarians, ${ }^{37}$ it is likely that the majority with amyloid or tau pathology in our study will not develop dementia during the coming decade. However, even if development of dementia is rare in this age group, cognitively healthy individuals with amyloid pathology on PET or CSF decline faster in cognitive function. $^{38}$

Among the strengths of this study are the representative population-based sample, the relatively high response rate for LP, and the comprehensive examinations conducted by trained psychiatric nurses. Some limitations need to be addressed. Even if the number with CSF data in this study was relatively large, the overall number is relatively low, yielding low statistical power (i.e., subsamples). More than one-third consented to LP, but almost one-quarter was excluded because of contraindications, illustrating the challenges of conducting population-based CSF research. Although participants with CSF data were similar to the rest of the sample regarding several factors, it is possible that participants were healthier, thus creating selection bias and not true prevalence figures. However, weighted prevalence figures using propensity score modeling were very similar to the unweighted prevalence. We have most likely underestimated the true prevalence of pathology. Moreover, it is possible that there have been subtle cognitive differences between the biomarker groups that were not detected with our brief and unspecific cognitive tests. A further limitation is that we did not use PET scans. However, the correlation between CSF $\mathrm{A} \beta_{42}$ and PET has been shown to be high, ${ }^{14}$ while markers of neurodegeneration are less concordant. ${ }^{8}$ Finally, this is a population-based study examining Swedish 70-year-olds; therefore, results cannot be generalized to other groups.

\section{Author contributions}

Silke Kern analyzed and interpreted the data, conducted the literature search, and wrote the paper. Kaj Blennow, Ulf Andreasson, and Henrik Zetterberg contributed with acquisition of data (CSF analyses) and study supervision. Kaj Blennow, Henrik Zetterberg, Jürgen Kern, Anna Zettergren, Kina Höglund, Ulf Andreasson, Hanna Wetterberg, Margda Waern, and Anne Börjesson-Hanson contributed with the analysis and interpretation of the data and revised the article critically for important intellectual content. Ingmar Skoog was principal investigator, conceived and designed the study, refined the study methods, was involved in analysis and interpretation of the data, and revised the article critically for important intellectual content. The corresponding author attests that the authors had access to all the study data, take responsibility for the accuracy of the analysis, and had authority over manuscript preparation and the decision to submit the manuscript for publication. All authors gave final approval of the version to be published. The corresponding author affirms that she has listed everyone who contributed significantly to the work. 


\section{Acknowledgment}

Valter Sundh, University of Gothenburg, performed the statistical analysis.

\section{Study funding}

This study was supported by grants from the Swedish Research Council (2012-5041, 2013-8717, 2015-02830), Swedish Research Council for Health, Working Life and Welfare (2013-1202, AGECAP 2013-2300, 2013-2496, 20130475), Swedish Alzheimerfoundation, Hjärnfonden, Stena Foundation, Sahlgrenska University Hospital (ALF), Torsten Söderbergs Stiftelse at the Royal Swedish Academy of Sciences, the Knut and Alice Wallenberg Foundation, the Emil and Maria Palm Foundation, Alma och Anna Ylen's Foundation, Konung Gustaf V:s och Drottning Victorias Frimurarestiftelse, Eivind och Elsa K:son Sylvans stiftelse, Stiftelsen SöderströmKönigska Sjukhemmet, Stiftelsen för Gamla Tjänarinnor, Handlanden Hjalmar Svenssons Forskningsfond, Stiftelsen Demensfonden, Stiftelsen Wilhelm and Martina Lundgrens Vetenskapsfond, Stiftelsen Professor Bror Gadelius' Minnesfond, the Göteborg Medical Services and Social Services Administrations, and Fredrik and Rosa von Malborgs Foundation for Brain Research.

\section{Disclosure}

S. Kern reports no disclosures relevant to the manuscript. $\mathrm{H}$. Zetterberg is a cofounder of Brain Biomarker Solutions in Gothenburg AB, a GU Ventures-based platform company at the University of Gothenburg (This company was not involved in any aspect of the study). J. Kern, A. Zettergren, M. Waern, K. Höglund, U. Andreasson, H. Wetterberg, and A. Börjesson-Hanson report no disclosures relevant to the manuscript. K. Blennow is a cofounder of Brain Biomarker Solutions in Gothenburg AB, a GU Ventures-based platform company at the University of Gothenburg. Dr. Blennow has served at advisory boards or as a consultant for Alzheon, Eli Lilly, Fujirebio Europe, IBL International, Pfizer, Roche Diagnostics, Amgen, and Sanofi-Aventis (unrelated to the present study) and has received research support from Janssen Alzheimer Immunotherapy and Roche Diagnostics (unrelated to the present study). I. Skoog reports no disclosures relevant to the manuscript. Go to Neurology.org/ $\mathrm{N}$ for full disclosures.

Received September 28, 2017. Accepted in final form February 20, 2018.

\section{References}

1. Blennow K, de Leon MJ, Zetterberg H. Alzheimer's disease. Lancet 2006;368: $387-403$.

2. Tomlinson BE, Blessed G, Roth M. Observations on the brains of non-demented old people. J Neurol Sci 1968;7:331-356.

3. Neuropathology Group, Medical Research Council Cognitive Function and Aging Study. Pathological correlates of late-onset dementia in a multicentre, community-based population in England and Wales: Neuropathology Group of the Medical Research Council Cognitive Function and Ageing Study (MRC CFAS). Lancet 2001;357:169-175.

4. Aizenstein HJ, Nebes RD, Saxton JA, et al. Frequent amyloid deposition without significant cognitive impairment among the elderly. Arch Neurol 2008;65:1509-1517.

5. Jack CR Jr, Lowe VJ, Weigand SD, et al. Serial PIB and MRI in normal, mild cognitive impairment and Alzheimer's disease: implications for sequence of pathological events in Alzheimer's disease. Brain 2009;132:1355-1365.

6. Pike KE, Savage G, Villemagne VL, et al. Beta-amyloid imaging and memory in nondemented individuals: evidence for preclinical Alzheimer's disease. Brain 2007;130: 2837-2844.
7. Dubois B, Feldman HH, Jacova C, et al. Advancing research diagnostic criteria for Alzheimer's disease: the IWG-2 criteria. Lancet Neurol 2014;13:614-629.

8. Vos SJ, Gordon BA, Su Y, et al. NIA-AA staging of preclinical Alzheimer disease: discordance and concordance of CSF and imaging biomarkers. Neurobiol Aging 2016;44:1-8.

9. Vos SJ, Xiong C, Visser PJ, et al. Preclinical Alzheimer's disease and its outcome: a longitudinal cohort study. Lancet Neurol 2013;12:957-965.

10. Hoglund K, Kern S, Zettergren A, et al. Preclinical amyloid pathology biomarker positivity: effects on tau pathology and neurodegeneration. Transl Psychiatry 2017;7:e995.

11. Stomrud E, Minthon L, Zetterberg H, Blennow K, Hansson O. Longitudinal cerebrospinal fluid biomarker measurements in preclinical sporadic Alzheimer's disease: a prospective 9-year study. Alzheimers Dement (Amst) 2015;1:403-411.

12. Bateman RJ, Xiong C, Benzinger TL, et al. Clinical and biomarker changes in dominantly inherited Alzheimer's disease. N Engl J Med 2012;367:795-804.

13. Fagan AM, Head D, Shah AR, et al. Decreased cerebrospinal fluid Abeta(42) correlates with brain atrophy in cognitively normal elderly. Ann Neurol 2009;65:176-183.

14. Sutphen CL, Jasielec MS, Shah AR, et al. Longitudinal cerebrospinal fluid biomarker changes in preclinical Alzheimer disease during middle age. JAMA Neurol 2015;72: 1029-1042.

15. Jack CR Jr, Knopman DS, Jagust WJ, et al. Tracking pathophysiological processes in Alzheimer's disease: an updated hypothetical model of dynamic biomarkers. Lancet Neurol 2013;12:207-216.

16. Jack CR Jr, Bennett DA, Blennow $\mathrm{K}$, et al. A/T/N: an unbiased descriptive classification scheme for Alzheimer disease biomarkers. Neurology 2016;87:539-547.

17. Dubois B, Hampel H, Feldman HH, et al. Preclinical Alzheimer's disease: definition, natural history, and diagnostic criteria. Alzheimers Dement 2016;12:292-323.

18. Sperling RA, Aisen PS, Beckett LA, et al. Toward defining the preclinical stages of Alzheimer's disease: recommendations from the National Institute on Aging-Alzheimer's Association workgroups on diagnostic guidelines for Alzheimer's disease. Alzheimers Dement 2011;7:280-292.

19. Jack CR Jr, Knopman DS, Weigand SD, et al. An operational approach to National Institute on Aging-Alzheimer's Association criteria for preclinical Alzheimer disease. Ann Neurol 2012;71:765-775.

20. Skoog I, Borjesson-Hanson A, Kern S, et al. Decreasing prevalence of dementia in 85year olds examined 22 years apart: the influence of education and stroke. Sci Rep 2017;7:6136.

21. Skoog I, Nilsson L, Palmertz B, Andreasson LA, Svanborg A. A population-based study of dementia in 85-year-olds. N Engl J Med 1993;328:153-158.

22. Kern S, Skoog I, Ostling S, Kern J, Borjesson-Hanson A. Does low-dose acetylsalicylic acid prevent cognitive decline in women with high cardiovascular risk? A 5-year follow-up of a non-demented population-based cohort of Swedish elderly women. BMJ Open 2012:2:e01288.

23. Kern J, Kern S, Blennow K, et al. Calcium supplementation and risk of dementia in women with cerebrovascular disease. Neurology 2016;87:1674-1680.

24. Bjerke M, Kern S, Blennow K, et al. Cerebrospinal fluid fatty acid-binding protein 3 is related to dementia development in a population-based sample of older adult women followed for 8 years. J Alzheimers Dis 2016;49:733-741.

25. Vanmechelen E, Vanderstichele H, Davidsson P, et al. Quantification of tau phosphorylated at threonine 181 in human cerebrospinal fluid: a sandwich ELISA with a synthetic phosphopeptide for standardization. Neurosci Lett 2000;285:49-52.

26. Blennow K, Wallin A, Agren H, Spenger C, Siegfried J, Vanmechelen E. Tau protein in cerebrospinal fluid: a biochemical marker for axonal degeneration in Alzheimer disease? Mol Chem Neuropathol 1995;26:231-245.

27. Andreasen N, Hesse C, Davidsson P, et al. Cerebrospinal fluid beta-amyloid(1-42) in Alzheimer disease: differences between early- and late-onset Alzheimer disease and stability during the course of disease. Arch Neurol 1999;56:673-680.

28. Steen Jensen C, Portelius E, Siersma V, et al. Cerebrospinal fluid amyloid beta and tau concentrations are not modulated by 16 weeks of moderate- to high-intensity physical exercise in patients with Alzheimer disease. Demen Geriatr Cogn Disord 2016;42:146-158.

29. Shaw LM, Vanderstichele H, Knapik-Czajka M, et al. Cerebrospinal fluid biomarker signature in Alzheimer's Disease Neuroimaging Initiative subjects. Ann Neurol 2009; 65:403-413.

30. Rowe CC, Ellis KA, Rimajova M, et al. Amyloid imaging results from the Australian Imaging, Biomarkers and Lifestyle (AIBL) study of aging. Neurobiol Aging 2010;31: 1275-1283.

31. Jack CR Jr, Wiste HJ, Weigand SD, et al. Age-specific and sex-specific prevalence of cerebral beta-amyloidosis, tauopathy, and neurodegeneration in cognitively unimpaired individuals aged 50-95 years: a cross-sectional study. Lancet Neurol 2017;16:435-444.

32. Crary JF, Trojanowski JQ, Schneider JA, et al. Primary age-related tauopathy (PART): a common pathology associated with human aging. Acta Neuropathol 2014;128:755-766.

33. Wang HF, Tan L, Cao L, et al. Application of the IWG-2 diagnostic criteria for Alzheimer's disease to the ADNI. J Alzheimers Dis 2016;51:227-236.

34. Ossenkoppele R, Jansen WJ, Rabinovici GD, et al. Prevalence of amyloid PET positivity in dementia syndromes: a meta-analysis. JAMA 2015;313:1939-1949.

35. Jansen WJ, Ossenkoppele R, Knol DL, et al. Prevalence of cerebral amyloid pathology in persons without dementia: a meta-analysis. JAMA 2015;313:1924-1938.

36. Jack CR Jr, Wiste HJ, Weigand SD, et al. Age, sex, and APOE epsilon4 effects on memory, brain structure, and beta-amyloid across the adult life span. JAMA Neurol 2015;72:511-519.

37. Hebert LE, Scherr PA, Bienias JL, Bennett DA, Evans DA. Alzheimer disease in the US population: prevalence estimates using the 2000 census. Arch Neurol 2003;60:1119-1122.

38. van Harten AC, Smits LL, Teunissen CE, et al. Preclinical AD predicts decline in memory and executive functions in subjective complaints. Neurology 2013;81:1409-1416. 


\title{
Prevalence of preclinical Alzheimer disease
}

\section{Comparison of current classification systems}

\author{
Silke Kern, MD, PhD, Henrik Zetterberg, MD, PhD, Jürgen Kern, MD, PhD, Anna Zettergren, PhD, \\ Margda Waern, MD, PhD, Kina Höglund, PhD, Ulf Andreasson, PhD, Hanna Wetterberg, MSc, \\ Anne Börjesson-Hanson, MD, PhD, Kaj Blennow, MD, PhD, and Ingmar Skoog, MD, PhD
}

Correspondence

Dr. S. Kern

silke.kern@neuro.gu.se

Cite as: Neurology ${ }^{\circledR}$ 2018;90:e1682-e1691. doi:10.1212/WNL.0000000000005476

\section{Study question}

What is the prevalence of preclinical Alzheimer disease (AD) in the general population of 70-year-olds according to current CSF biomarker-based classification systems?

\section{Summary answer}

According to current CSF biomarker-based classification systems, almost half of 70-year-olds have preclinical $\mathrm{AD}$ or a related condition.

\section{What is known and what this paper adds}

Many elderly persons without dementia exhibit preclinical AD pathology. This study of a representative population clarifies the prevalence of preclinical $\mathrm{AD}$ pathology according to the criteria of 4 classification systems introduced between 2011 and 2016.

\section{Participants and setting}

This study examined 259 residents (50.2\% male) of Gothenburg, Sweden, who were born in 1944, had no contraindications to lumbar puncture, and were considered cognitively unimpaired due to having a Clinical Dementia Rating score of 0 . The examinations occurred at Sahlgrenska University Hospital between 2014 and 2016 as part of the H70 Gothenburg Birth Cohort Studies.

\section{Design, size, and duration}

CSF samples were collected via lumbar puncture. $\mathrm{AD}$ biomarkers including total tau, threonine-181-phosphorylated tau, and $\beta$-amyloid $42\left(A \beta_{42}\right)$ and $A \beta_{42} / A \beta_{40}$ ratios were quantified with commercially available immunoassays.

\section{Primary outcomes}

The primary outcomes were CSF biomarker-based classifications of $\mathrm{AD}$ pathology according to the $\mathrm{A} / \mathrm{T} / \mathrm{N}$ scheme, the Dubois 2016 criteria, the International Working Group-2 (IWG-2) criteria, and the NIA-AA criteria.

\section{Main results}

Under the $\mathrm{A} / \mathrm{T} / \mathrm{N}$ scheme, $46.2 \%$ of participants were positive for $\geq 1 \mathrm{AD}$ biomarker. Under the Dubois 2016 criteria, $36.7 \%$ of participants were asymptomatic-at-risk-for $\mathrm{AD}$, and

\begin{tabular}{|c|c|}
\hline $\mathrm{A} / \mathrm{T} / \mathrm{N}$ classification & No. $(\%)$ of participants \\
\hline $\mathrm{A}+/ \mathrm{T}-/ \mathrm{N}-$ & $34(13.1)$ \\
\hline $\mathrm{A}+/ \mathrm{T}-/ \mathrm{N}+$ & $19(7.3)$ \\
\hline $\mathrm{A}+/ \mathrm{T}+/ \mathrm{N}+$ & $6(2.3)$ \\
\hline $\mathrm{A}-/ \mathrm{T}-/ \mathrm{N}+$ & 49 (18.9) \\
\hline $\mathrm{A}-/ \mathrm{T}+/ \mathrm{N}+$ & $12(4.6)$ \\
\hline
\end{tabular}

Abbreviations: $A \beta=\beta$-amyloid; $p$-tau = phosphorylated tau; $\mathrm{t}$-tau = total tau.

9.7\% of participants had preclinical AD. Under the IWG-2 criteria, $9.7 \%$ of participants were asymptomatic at risk for $\mathrm{AD}$. Under the NIA-AA criteria, $22.8 \%$ of participants had preclinical $\mathrm{AD}$.

\section{Bias, confounding, and other reasons for caution}

The exclusion of study candidates with contraindications to lumbar puncture might have biased the study sample towards relatively healthy participants, so the prevalence of preclinical $\mathrm{AD}$ might have been underestimated. PET data were unavailable, so PET criteria in the IWG-2 and NIA-AA schemes could not be applied. There was no pathologic confirmation of $\mathrm{AD}$.

\section{Generalizability to other populations}

The generalizability to populations unlike 70 -year-old residents of Sweden may be limited.

\section{Study funding/potential competing interests}

This study was funded by the Swedish government, various foundations, and Sahlgrenska University Hospital. Dr. Zetterberg and Dr. Blennow cofounded Brain Biomarker Solutions. Dr. Blennow reports receiving funding, advisory board appointments, and consulting fees from various healthcare companies. Go to Neurology.org/N for full disclosures. 


\section{Neurology}

\section{Prevalence of preclinical Alzheimer disease: Comparison of current classification systems}

Silke Kern, Henrik Zetterberg, Jürgen Kern, et al.

Neurology 2018;90;e1682-e1691 Published Online before print April 13, 2018

DOI 10.1212/WNL.0000000000005476

This information is current as of April 13, 2018

\section{Updated Information \&} Services

References

Citations

Subspecialty Collections

Permissions \& Licensing

Reprints including high resolution figures, can be found at: http://n.neurology.org/content/90/19/e1682.full

This article cites 38 articles, 3 of which you can access for free at: http://n.neurology.org/content/90/19/e1682.full\#ref-list-1

This article has been cited by 5 HighWire-hosted articles: http://n.neurology.org/content/90/19/e1682.full\#\#otherarticles

This article, along with others on similar topics, appears in the following collection(s):

Alzheimer's disease

http://n.neurology.org/cgi/collection/alzheimers_disease

Cohort studies

http://n.neurology.org/cgi/collection/cohort_studies

Prevalence studies

http://n.neurology.org/cgi/collection/prevalence_studies

Information about reproducing this article in parts (figures,tables) or in its entirety can be found online at:

http://www.neurology.org/about/about_the_journal\#permissions

Information about ordering reprints can be found online:

http://n.neurology.org/subscribers/advertise

Neurology ${ }^{\circledR}$ is the official journal of the American Academy of Neurology. Published continuously since 1951, it is now a weekly with 48 issues per year. Copyright Copyright ( 2018 The Author(s). Published by Wolters Kluwer Health, Inc. on behalf of the American Academy of Neurology.. All rights reserved. Print ISSN: 0028-3878. Online ISSN: 1526-632X.

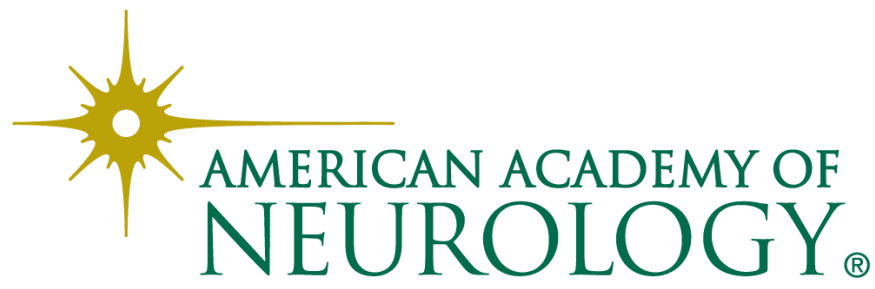

